AJChE 2018, Vol. 18, No. 1, $09-16$

\title{
Removing Ethylene by Adsorption using Cobalt Oxide-Loaded Nanoporous Garbon
}

\author{
Imam Prasetyo *,1,2 \\ Nur Indah Fajar Mukti ${ }^{3}$ \\ Moh Fahrurrozi ${ }^{1}$ \\ Teguh Ariyanto *,1,2 \\ ${ }^{1}$ Department of Chemical Engineering, Faculty of Engineering, Universitas Gadjah Mada, 55281 \\ Yogyakarta, Indonesia \\ ${ }^{2}$ Advanced Material and Sustainable Mineral Processing Research Group, Faculty of Engineering, \\ Universitas Gadjah Mada, 55281 Yogyakarta, Indonesia \\ 3 Department of Chemical Engineering, Islamic University of Indonesia, 55584 Yogyakarta, \\ Indonesia \\ *e-mail: imampras@ugm.ac.id; teguh ariyanto@ugm.ac.id
}

Ethylene is naturally generated by climacteric fruits and can promote the ripening process faster. For effective long-distance transport and subsequent storage, removing ethylene from the storage environment has been of interest to suppress its undesirable effect. In this study, ethylene removal by an adsorptive method using cobalt-loaded nanoporous carbon is studied. Cobalt oxide-loaded carbon was prepared by incipient wetness method followed by calcination process at $200{ }^{\circ} \mathrm{C}$ under inert flow. Ethylene adsorption test was performed at 20,30 , and $40{ }^{\circ} \mathrm{C}$ using a static volumetric test. The results showed that cobalt oxide/carbon system has significant ethylene adsorption capacity up to 3.5 times higher compared to blank carbon. A higher temperature adsorption is more favorable for this chemisorption process. Ethylene uptake increases from 100 to $150 \mathrm{~mL} \mathrm{~g}^{-1}$ adsorbent STP by increasing cobalt oxide loading on carbon from 10 to $30 \mathrm{wt} . \% \mathrm{Co}$. The highest uptake capacity of $6 \mathrm{mmol}$ ethylene per gram adsorbent was obtained using $30 \mathrm{wt} . \%$ cobalt oxide. Therefore, ethylene adsorption by cobalt-loaded nanoporous carbon may represent a potential method in ethylene removal and it could serve as a basis for development of ethylene scavenging material.

Keywords: adsorption, cobalt-oxide, ethylene scavenger, porous carbon

\section{INTRODUCTION}

Ethylene has long been recognized as a problem in post-harvest handling of horticultural products (Abe and Watada, 1991; Biale et al., 1953). In a very small concentration (in the order of $\mathrm{ppb}$ ), ethylene is physiologically active and will cause a faster deterioration of fresh products (Keller et al., 2013). It is necessary, therefore, to maintain the atmosphere of the packaging of the products at a very low concentration of ethylene during longdistance shipping and storage. Methods for 
controlling and removing ethylene can be conducted by ventilation, oxidation using potassium permanganate (Singh and Giri, 2014; Wills and Warton, 2004) and adsorption using adsorbent materials (Cao et al., 2015).

Adsorption method can be efficiently used to achieve a very selective separation process for removing a small quantity of contaminant species from a fluid system. This technique has been considered to be superior to other technique for contaminant removal in view of its comparatively low cost, easy operation, and facile regeneration of the adsorbent (Keller et al., 2013; Martínez-Romero et al., 2007). Efforts on adsorbent development for ethylene have been performed by various research groups (Cao et al., 2015; MartínezRomero et al., 2007; Sue-Aok et al., 2010)

In this work, we investigate the use of composite of metal oxide/carbon as an adsorbent for ethylene scavenger. Porous carbon was employed as host material for the metal oxide. Porous carbon is chosen due to its excellent characteristics of high specific surface area (Ariyanto et al., 2017b; Prasetyo et al., 2017, 2013). Cobalt oxide was impregnated within the carbon pore network to utilize the ability of this metal oxide to selectively adsorb ethylene from the atmosphere (Prasetyo, 2000). Porous carbon with special pore structures in this work was prepared from biomass/renewable resources of mangosteen shell.

The major goal of the studies described in this paper was to investigate the use of cobalt-oxide impregnated carbon as a potentially efficient material for ethylene removal.

\section{METHODOLOGY/EXPERIMENTAL}

\section{Material Preparation}

Porous carbon was synthesized by carbonization mangosteen shell (Bina Agro Mandiri, Indonesia) at $850^{\circ} \mathrm{C}$. The carbon was subsequently labelled as Mangosteen Shell Carbon (MSC). To disperse cobalt oxide in carbon, incipient wetness method of cobalt precursor followed by calcination process was carried out (impregnation method, see (Ariyanto et al., 2017a)). Carbon and solution of cobalt nitrate (99.8\%, Merck) was mixed by ultrasonication. The target of cobalt on cobalt oxide/carbon was set to 10,20 , and 30 wt.\%. After evaporation of solvent, calcination process was carried out at $200{ }^{\circ} \mathrm{C}$ under nitrogen flow in a quartz tubular reactor. The final material produced was labelled as $\mathrm{X} \% \mathrm{Co} / \mathrm{MSC}$. For example, $10 \% \mathrm{Co} / \mathrm{MSC}$ refers to $10 \mathrm{wt} . \%$ loading of $\mathrm{Co}$ in the MSC carbon.

\section{Material Characterization}

The properties of materials were characterized using $\mathrm{N}_{2}$-sorption (Quantachrome NOVA 2000), and scanning electron microscopy JSM-6510 LA (JEOL) at $15 \mathrm{kV}$ voltage.

\section{Ethylene Adsorption Isotherm Measurement}

The uptake capacity of ethylene (PT Samator Indonesia) in cobalt oxide-loaded porous carbon was determined using a static volumetric method with and adsorption rig constructed by Swagelok VCR ${ }^{\circledR}$ fittings (supplied by PT Putranata Adi Mandiri, Jakarta, Indonesia). The adsorption 


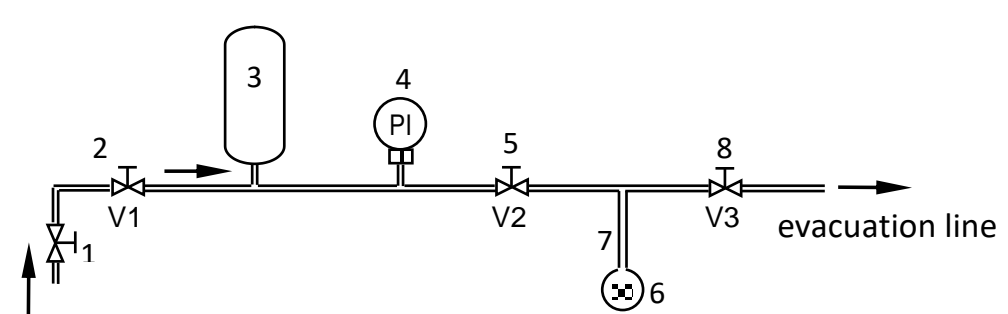

ethylene dose line
1. Ethylene inlet

2. Inlet valve

3. Ethylene reservoir

4. Pressure transducer

5. Dosing valve

6. Adsorbent sample

7. Sample cell

8. Evacuation valve

Fig. 1: Schematic diagram of equilibrium adsorption measurement

rig for isotherm test is shown in Figure 1. It was conducted by dosing ethylene in gradual amount and detecting the equilibrium pressure. The adsorption temperature was controlled at i.e. 20, 30 and $40{ }^{\circ} \mathrm{C}$. Isotherm was recorded in the range of 0-760 Torr by pressure transducer (type 910 DualTrans, supplied by MKS Company Singapore).

\section{Ethylene Adsorption Kinetic Measurement}

The adsorption rate measurements were carried out in a batch adsorber and the experimental set up is shown in Figure 2. In this dynamic adsorption, ethylene contained in a reservoir (see 1, in Figure 2) was simply introduced into a preevacuated adsorption cell (2\&3). The pressure of the cell was monitored as a function of time and the analyzed by means of mathematical model to give values of dynamic parameters. The adsorption kinetics experiment was carried out at different adsorbate loading, to determine the diffusivity as a function of loading.

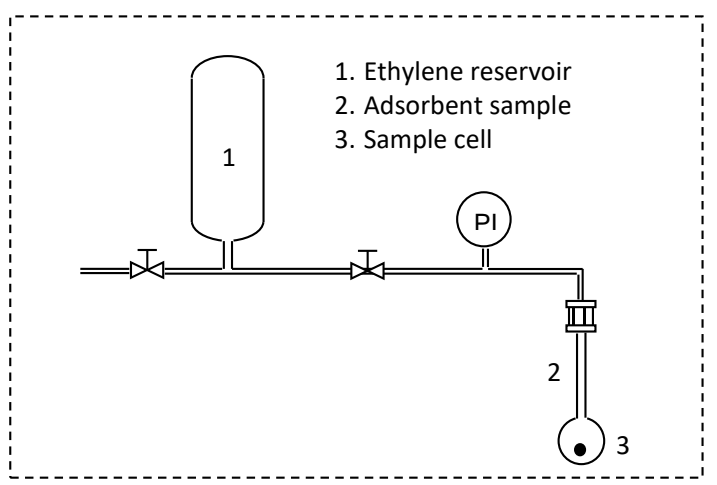

Fig. 2: Schematic diagram of adsorption rate measurement

To analyze the experimental data collected in the experiments, the mass transfer is assumed to be controlled by the dual flow of adsorbate into the interior of the particle. The constitutive flux equation accounting for this dual flow of molecule is:

$$
J=-\varepsilon D_{p} \frac{\partial C}{\partial r}-(1-\varepsilon) D_{\mu} \frac{\partial C_{\mu}}{\partial r}
$$

The mass balance equation for describing the adsorbate distribution in the particle is given by:

$$
\begin{aligned}
\varepsilon \frac{\partial C}{\partial t}+(1-\varepsilon) \frac{\partial C_{\mu}}{\partial t} & =\varepsilon D_{p} \frac{1}{r^{s}} \frac{\partial}{\partial r}\left(r^{s} \frac{\partial C}{\partial r}\right) \\
& +(1-\varepsilon) D_{\mu} \frac{1}{r^{s}} \frac{\partial}{\partial r}\left(r^{s} \frac{\partial C_{\mu}}{\partial r}\right)
\end{aligned}
$$


where $\varepsilon$ is the porosity, $C$ is the fluid concentration (using ideal gas, $C=P / R T$ ), $C_{\mu}$ is the concentration in the adsorbed phase, $D_{p}$ is the pore diffusivity, $D_{\mu}$ is the surface diffusivity, and $s$ is the particle shape factor ( $s=0,1$ and 2 for slab, cylinder and sphere, respectively).

Assuming local linear isotherm constant $\left(C_{\mu}=K C\right)$ and spherical geometry of the particle, Equation 2 becomes:

$$
\frac{\partial C}{\partial t}=D_{a p p} \frac{1}{r^{2}} \frac{\partial}{\partial r}\left[r^{2} \frac{\partial C}{\partial r}\right]
$$

with $D_{a p p}$ the apparent diffusivity which embeds both two diffusion coefficients and slope of isotherm. $D_{a p p}$ is defined as follows:

$$
D_{a p p}=\frac{\varepsilon D_{p}+(1-\varepsilon) K D_{\mu}}{\varepsilon+(1-\varepsilon) K}
$$

If the adsorbed species is rather immobile (strongly adsorbed to the surface), the contribution of surface diffusion can be neglected compare to that of pore diffusion, that is $(1-\varepsilon) K D_{\mu}<<\varepsilon D_{p}$, the apparent diffusivity will become Equation 5 .

$$
D_{a p p}=\frac{\varepsilon D_{p}}{\varepsilon+(1-\varepsilon) K}
$$

\section{RESULTS AND DISCUSSION}

\section{Material Synthesis}

Pore structure of carbon produced by pyrolysis of mangosteen shell was characterized by $\mathrm{N}_{2}$-sorption analysis. Figure 3A displays isotherm recorded in the range of $0-760$ Torr. MSC shows a characteristic Type IV isotherm according IUPAC classification for mesoporous material (Thommes et al., 2015). For comparison, commercial activated carbon (CAC) produced from pyrolysis of coconut shell exhibits only micropores as shown by Type I isotherm. Both materials exhibit a similar BET specific surface area of ca. 1000 $\mathrm{m}^{2} / \mathrm{g}$. From the isotherm, pore size distributions can be evaluated and are shown in Figure 3B. MSC possesses a
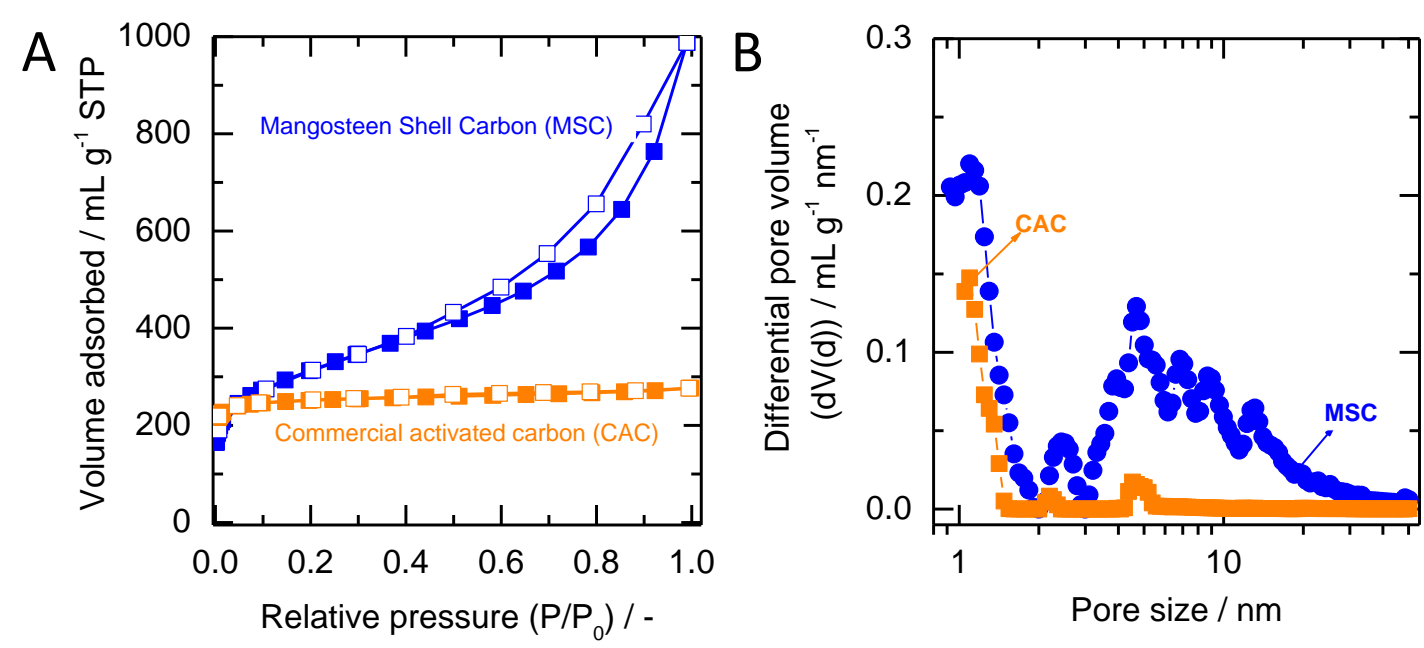

Fig. 3: (A) $\mathrm{N}_{2}$-sorption isotherm (A) and pore size distribution evaluated by QSDFT method (B) of porous carbon synthesized from mangosteen shell and commercially available activated carbon derived from coconut shell. 

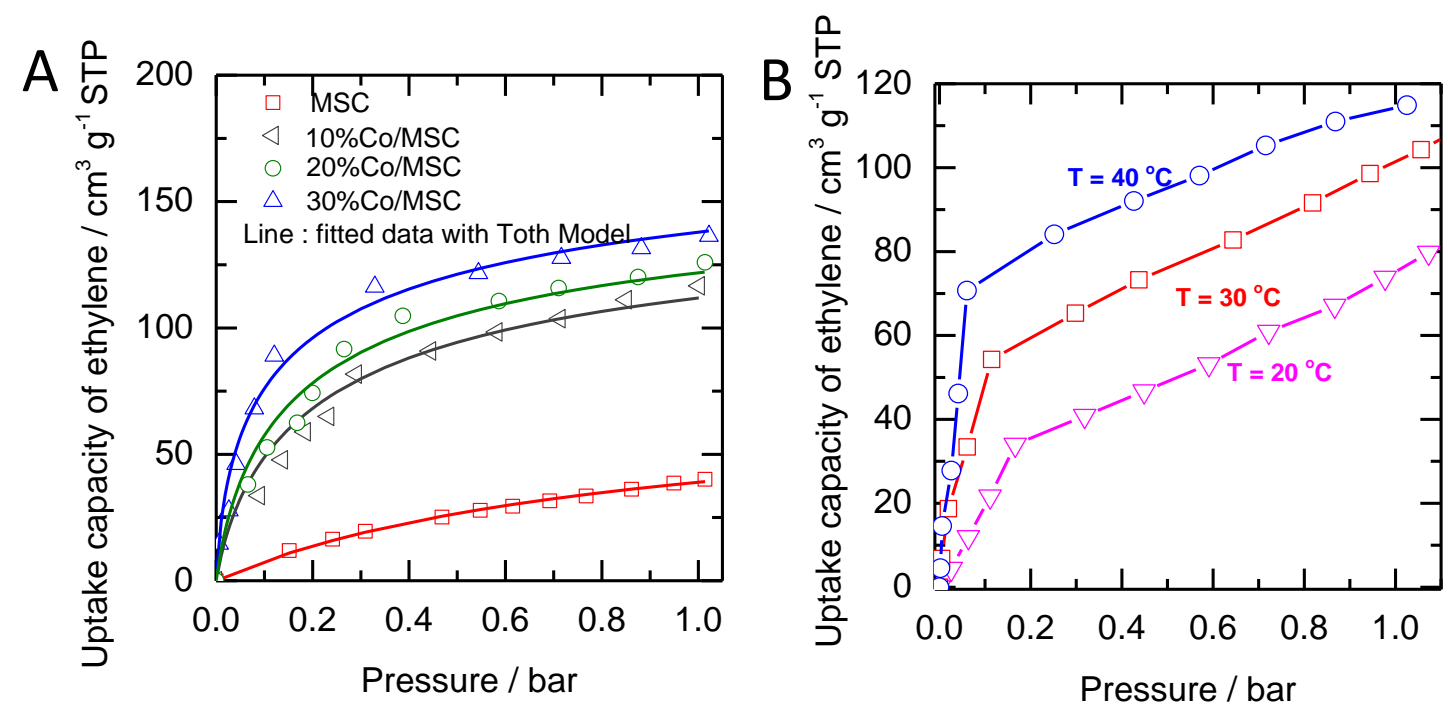

Fig. 4: (A) Uptake capacity of ethylene in material with different cobalt oxide content. (B) Adsorption of ethylene on $5 \% \mathrm{Co} / \mathrm{C}$ as temperature function.

substantial mesopores of 90 vol.\% $\left(2<d_{\text {pore }}\right.$ $<50 \mathrm{~nm}$ ) while CAC contains micropores of 80 vo.\% $\left(d_{\text {pore }}<2 \mathrm{~nm}\right)$. Therefore, MSC shows a comparable quality with the commercial activated carbon in the term of specific surface area. But, MSC has abundant mesopores which are important for cobalt precursor mobility during synthesis of cobalt oxide-loaded in porous carbon.

The MSC was then impregnated by cobalt oxide. SEM-EDX characterization displayed that cobalt oxide can be homogenously dispersed on carbon surface (data not shown). The EDX analysis also showed a precise tuning of cobalt content by a simple stoichiometric formula. For instance, Co contents obtained by EDX analysis for $30 \% \mathrm{Co} / \mathrm{MSC}$ is $30.5 \pm 1.2 \%$.

\section{Ethylene Adsorption Isotherm}

The performance of cobalt oxide-loaded porous carbon for adsorbing ethylene was measured. Firstly, MSC carbon without cobalt oxide was used (Figure 4A). The result shows only little volume of ethylene can be adsorbed $\left(38 \mathrm{~cm}^{3} / \mathrm{g}\right.$ adsorbent at
STP). When introducing cobalt oxide with $10 \%$ loading, a boosting adsorption can be seen. The enhancement of uptake capacity up to 3 times results $\left(110 \mathrm{~cm}^{3} / g\right.$ adsorbent at STP) when compared to pristine MSC. Further increasing the cobalt loading can further extent the uptake capacity up to $140 \mathrm{~cm}^{3} / \mathrm{g}$ adsorbent (STP).

The effect of temperature on the uptake capacity was evaluated. The material used for the experiment was $5 \% \mathrm{Co} / \mathrm{MSC}$. As shown in Figure $\mathbf{4 B}$, ethylene uptake is more favorable when using a higher temperature condition. The indication of more ethylene uptake at higher temperature suggests that chemisorption mechanism is the likely one to describe the adsorption of ethylene by the adsorbent. The uptake capacity of ethylene at $1 \mathrm{bar}$ pressure is in the range of $70-115 \mathrm{~cm}^{3} / \mathrm{g}$ adsorbent (STP). This adsorptive behavior of cobalt oxide/carbon would be an advantage when adsorbing ethylene for fruit preservation during storage. It is since the storage of fruit typically results in an increase of temperature. 


\section{Ethylene Adsorption Kinetics}

In addition to equilibrium characteristic, adsorption dynamics properties were also determined to provide a basis for estimation of the process performance and process design parameters. The typical curve for recorded pressure vs. time during adsorption is shown in Figure $\mathbf{5}$.

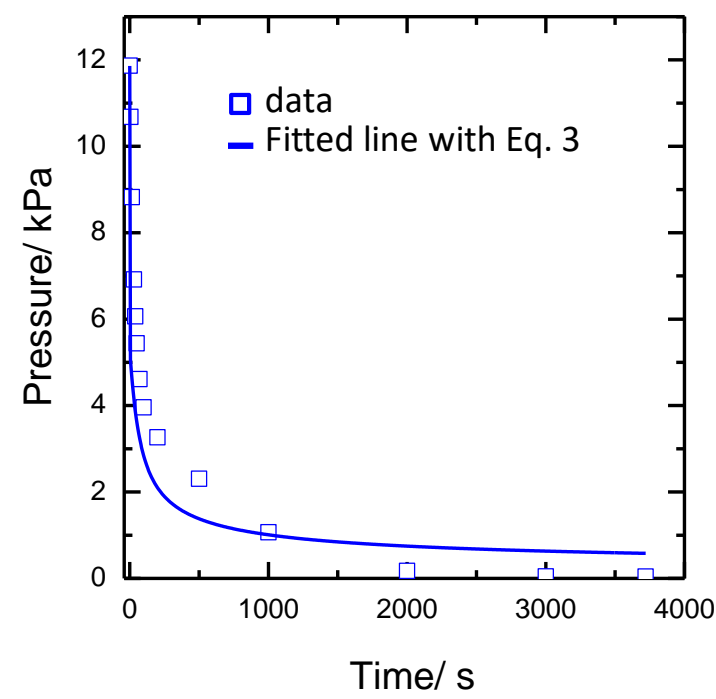

Fig. 5: The monitored pressure during kinetics measurement at ethylene loading of $0.87 \mathrm{mmol}$ ethylene $/ \mathrm{cm}^{3}$ solid. Data fitted with intraparticle gradient model employing dual flow of adsorbate.

Figure 5 exhibits that initially, the ethylene can be adsorbed fast from the bulk and after a certain time, the adsorption rate becomes slower. This is likely due to low driving forces when ethylene is dominantly adsorbed in the cobalt oxide/carbon. The evaluation using in intraparticle gradient model employing dual flow of adsorbate shows that data can be well fitted, resulting $D_{a p p}$ value of $1 \times 10^{-8} \mathrm{~m}^{2} / \mathrm{s}$. When using different ethylene loading on cobalt oxide/carbon, the similar value of apparent diffusivity results (Table 1). It could indicate that pore diffusion plays important role which is likely due to ethylene is rather immobile (strongly adsorbed to the surface) when adsorbed in the adsorbent.

Table 1. Diffusivity at various ethylene loading

\begin{tabular}{cc}
\hline $\mathbf{C}_{\boldsymbol{\mu}, \mathbf{~} \mathbf{~ m o l} / \mathbf{c m}^{\mathbf{3}}}$ & $\boldsymbol{D}_{\text {app, }} \mathbf{~}^{\mathbf{2}} / \mathbf{s} \mathbf{\times 1 0 ^ { - 8 }}$ \\
\hline 0.87 & 1.00 \\
2.37 & 1.01 \\
4.41 & 1.03 \\
\hline
\end{tabular}

\section{CONCLUSIONS}

Porous carbon was produced by carbonization of mangosteen shell. $\mathrm{N}_{2}-$ sorption analysis displayed that carbon with substantial mesopores resulted. Characterization exhibited a successful loading of cobalt substances in nanoporous carbon. The uptake capacity test displayed ethylene is more favorably adsorbed in higher content of cobalt (range 0-30\% wt. Co) and a higher temperature condition. With a high ethylene uptake up to $140 \mathrm{~cm}^{3} / \mathrm{g}$ STP and fast adsorption process, the study demonstrated promising application of cobalt-loaded porous carbon for ethylene removal during storage of fruit.

\section{ACKNOWLEDGEMENTS}

The authors gratefully acknowledge the funding of the Ministry of Research, Technology and Higher Education of the Republic of Indonesia (MENRISTEKDIKTI) through Penelitian Unggulan Perguruan Tinggi (PUPT) (Grant No. 7437/UN1.P.III/DIT-LIT/LT/2017) and Penelitian Terapan Unggulan Perguruan Tinggi (PTUPT) (Grant No. 
1973/UN1/DITLIT/DIT-LIT/LT/2018). The authors thank PT. HOME System Indonesia for a gift of commercial activated carbon.

\section{REFERENCES}

1. Abe, K., Watada, A.E., 1991. Ethylene Absorbent to Maintain Quality of Lightly Processed Fruits and Vegetables. J. Food Sci. 56, 1589-1592. https://doi.org/10.1111/j.13652621.1991.tb08647.x

2. Ariyanto, T., Kern, A., Etzold, B.J.M., Zhang, G.-R., 2017a. Carbide-derived carbon with hollow core structure and its performance as catalyst support for methanol electro-oxidation. Electrochem. commun. 82, 12-15. https://doi.org/10.1016/j.elecom.2017. 07.010

3. Ariyanto, T., Zhang, G.-R., Riyahi, F., Gläsel, J., Etzold, B.J.M., 2017b. Controlled synthesis of core-shell carbide-derived carbons through in situ generated chlorine. Carbon N. Y. 115, 422-429.

https://doi.org/10.1016/j.carbon.2017. 01.032

4. Biale, J.B., Young, R.E., Olmstead, A.J., 1953. Fruit respiration and ethylene production. Plant Physiol. 29, 168-174. https://doi.org/10.1104/pp.37.2.179

5. Cao, J., Li, X., Wu, K., Jiang, W., Qu, G., 2015. Preparation of a novel $\mathrm{PdCl} 2$ CuSO4-based ethylene scavenger supported by acidified activated carbon powder and its effects on quality and ethylene metabolism of broccoli during shelf-life. Postharvest Biol. Technol. 99, 50-57.

https://doi.org/10.1016/j.postharvbio.2
014.07.017

6. Keller, N., Ducamp, M.N., Robert, D., Keller, V., 2013. Ethylene removal and fresh product storage: A challenge at the frontiers of chemistry. Toward an approach by photocatalytic oxidation. Chem. Rev. https://doi.org/10.1021/cr900398v

7. Martínez-Romero, D., Bailén, G., Serrano, M., Guillén, F., Valverde, J.M., Zapata, P., Castillo, S., Valero, D., 2007. Tools to maintain postharvest fruit and vegetable quality through the inhibition of ethylene action: a review. Crit. Rev. Food Sci. Nutr. 47, 543-560. https://doi.org/10.1080/104083906008 46390

8. Prasetyo, I., $2000 . \quad$ Kinetics characterization of hydrocarbons on activated carbon with new constant molar flow and differential permeation techniques. University of Queensland.

9. Prasetyo, I., Rochmadi, R., Wahyono, E., Ariyanto, T., 2017. Controlling synthesis of polymer-derived carbon molecular sieve and its performance for $\mathrm{CO} 2 / \mathrm{CH} 4$ separation. Eng. J. 21, 83-94. https://doi.org/10.4186/ej.2017.21.4.83

10. Prasetyo, I., Rochmadi, Ariyanto, T., Yunanto, R., 2013. Simple method to produce nanoporous carbon for various applications by pyrolysis of specially synthesized phenolic resin. Indones. J. Chem. 13, 95-100.

11. Singh, R., Giri, S., 2014. Shelf-life study of Guava under active packaging: An experiment with potassium permanganate salt as ethylene absorbent. J. Food Saf. Food Qual. 65, 32-39. https://doi.org/10.2376/0003925X-65-32 
12. Sue-Aok, N., Srithanratana, T., Rangsriwatananon, K., Hengrasmee, S., 2010. Study of ethylene adsorption on zeolite $\mathrm{NaY}$ modified with group I metal ions. Appl. Surf. Sci. 256, 3997-4002. https://doi.org/10.1016/j.apsusc.2010.0 1.065

13. Thommes, M., Kaneko, K., Neimark, A. V., Olivier, J.P., Rodriguez-Reinoso, F., Rouquerol, J., Sing, K.S.W., 2015. Physisorption of gases, with special reference to the evaluation of surface area and pore size distribution (IUPAC Technical Report). Pure Appl. Chem. 87. https://doi.org/10.1515/pac-20141117

14. Wills, R.B.H., Warton, M.A., 2004. Efficacy of potassium permanganate impregnated into alumina beads to reduce atmospheric ethylene. J. Amer. Soc. Hort. Sci. 129, 433-438. 